\title{
Trimethoprim-Sulphamethoxazole in Acute Osteomyelitis Due to Penicillin-resistant Staphylococci in Uganda
}

\author{
J. L. CRAVEN, ${ }^{*}$ M.D., F.R.C.S. ; D. J. PUGSLEY, $†$ M.R.C.P. \\ ROBERT BLOWERS, $\ddagger$ M.D., F.R.C.P., F.R.C.PATH.
}

British Medical fournal, 1970, 3, 201-203

\begin{abstract}
Cummary: Most recent cases of staphylococcal osteo$\checkmark$ myelitis seen at Mulago Hospital, Kampala, have been due to penicillin-resistant organisms. Six severely ill patients-four with multiple bone lesions-were treated with trimethoprim-sulphamethoxazole; the response was prompt and satisfactory in all cases.
\end{abstract}

\section{Introduction}

Acute and chronic haematogenous osteomyelitis are major clinical problems in Uganda, as in the rest of the developing world (British Medical fournal, 1967). About 200 patients with these conditions are admitted annually to Mulago Hospital. In contrast to a recent report (British Medical fournal, 1969), most of these-in whom the infecting agent is Staph. aureus - present in the early stages of the disease. Unfortunately, there is an increasing resistance to penicillin in staphylococci isolated from the Mulago patients. In a study of Staph. aureus acquired outside hospital in Uganda, 15\% were resistant to benzylpenicillin (Balmer et al., 1970). In staphylococci from acute osteomyelitis resistance is more frequently encountered, possibly because of inadequate therapy with penicillin before admission. Of the last 31 cases treated at Mulago 30 were due to staphylococci that were, by routine disc test, resistant to penicillin; though determination of the minimum inhibitory concentration (M.I.C.) showed that some of these patients might have been successfully treated with large doses of penicillin.

It is generally agreed that a bactericidal drug is superior to a bacteriostatic drug for treating acute osteomyelitis. For this reason, and because of the problem of penicillin-resistant staphylococci, the penicillinase-resistant penicillins, methicillin and cloxacillin, and the combination of Fucidin (sodium salt of fusidic acid) and methicillin (Jensen and Lassen, 1969) have been strongly recommended as tirst-choics antibiotics for the treatment of this condition. At present, however, the only bactericidal drug widely available in Uganda is penicillin. This is the background to the problem of osteomyelitis as it confronts the clinician in Uganda, and it prompted us to study the recently introduced bactericidal combination, trimethoprim-sulphamethoxazole, in acute osteomyelitis.

Trimethoprim is a synthetic and potent inhibitor of folate synthesis. Acting alone, it inhibits the growth of many species of bacteria; in combination with a sulphonamide-of which sulphamethoxazole seems most suitable-its action against sulphonamide-sensitive organisms is often potentiated, and is thought to be bactericidal (Garrod and Waterworth, 1968; Darrell et al., 1968). In human plasma concentrations of trimethoprim of $1 \mu \mathrm{g} . / \mathrm{ml}$. and sulphamethoxazole $20 \mu \mathrm{g} . / \mathrm{ml}$. are easily maintained. Balmer et al. (1970) have found that all 118 strains of Staph. aureus from Mulago patients were sensitive to attainable serum concentrations of trimethoprim and $70 \%$ to sulphamethoxazole. A trial of trimethoprim-sulphamethox-

\footnotetext{
*Senior Registrar, Department of Surgery, Mulago Hospital, Kampala, Uganda.

† Medical Officer, Special Grade, Mulago Hospital, Kampala, Uganda.

¥ Professor of Microbiology, Makerere College Medical School, Kampala. Present address: Public Health Laboratory, Ayresome Green Lane, Middlesbrough, Yorkshire.
}

azole combination for the treatment of acute staphylococcal osteomyelitis therefore seemed justifiable.

A controlled double-blind study of the effectiveness of a drug in osteomyelitis is not suitable in the relatively advanced cases seen in Uganda because of the possible and unpredictable occurrence of sequestra when intramedullary thrombosis and bone death have already occurred. Aware that the results of our trial have no statistical significance, we here report the results of treating six cases of staphylococcal osteomyelitis with trimethoprim and sulphamethoxazole.

\section{Material and Methods}

The drug combination used was Bactrim. Each sugarcoated "drapsule" contained trimethoprim $80 \mathrm{mg}$. and sulphamethoxazole $400 \mathrm{mg}$. Disc-diffusion sensitivity tests and minimum inhibitory concentration determinations were performed on lysed horse-blood agar as described by Darrell et al. (1968).

\section{Case Histories}

Case 1.-A 7-year-old girl, admitted from a neighbouring hospital with a history of pain and swelling in the left ankle, had received penicillin for three weeks. When first seen she was very ill with a temperature of $100^{\circ} \mathrm{F}$. $\left(37.8^{\circ} \mathrm{C}\right.$.) and pulse of 130 . There was tenderness over the upper ends of both femora and the lower left tibia, and there were signs of septic arthritis in both hips; radiography showed periosteal new-bone formation and patchy rarefaction at these sites. The right hip was subluxated posteriorly. The child was immobilized in a double hip spica and given one drapsule of Bactrim twice daily. Pus from the left ankle grew penicillin-resistant Staph. aureus. Within three days her temperature and pulse were normal and she was comfortable. Bactrim was continued for 10 weeks. Twenty weeks after the start of treatment there was no sign of recurrence.

Case 2.-A 13-year-old boy was admitted with 10 days' pain and swelling of the left hip, right knee, right elbow, and right shoulder. He was pyrexial, with tachycardia and signs of a septic effusion in the right elbow, from which penicillin-resistant Staph. aureus was grown. He was given two drapsules of Bactrim twice daily. He remained pyrexial until day 9. On day 7 Staph. aureus with the same sensitivities was grown from blood culture. He was maintained on Bactrim until the 45th day, and at that time had no signs of residual bone, joint, or systemic infection.

Case 3.-A 2-year-old girl was brought to the casualty department with a two-day history of a painful swollen left leg. $X$-ray examination of the leg showed no abnormality. A diagnosis of cellulitis was made and penicillin was prescribed. Two days later, as she was not improving, she was admitted to hospital. There was fluctuation over the middle of the tibia and $x$-ray examination showed the signs of early osteomyelitis. She was given Bactrim, one drapsule twice daily. Surgical drainage produced about $200 \mathrm{ml}$. of subperiosteal pus from which penicillin-resistant Staph. aureus was grown. Four days later her temperature was normal and she was discharged in a long leg plaster and for treatment with Bactrim for three more weeks. When seen four weeks later there were no signs of residual infection.

Case 4.-A 14-year-old boy presented with a two-week history of swelling of the left leg. One week before admission he had had an abscess of the leg incised and drained elsewhere and had been prescribed penicillin. On admission he was very ill with a temperature of $102^{\circ} \mathrm{F}$. $\left(39.9^{\circ} \mathrm{C}\right.$.). Tender swellings were present over the left tibia, both elbow joints, and the right clavicle. A chest $x$ - 
ray film showed generalized patchy bronchopneumonia. A diagnosis of staphylococcal septicaemia complicating multiple osteomyelitis was made. He was treated with erythromycin and novobiocin; cloxacillian was substituted when it became available. During the first two weeks in hospital abscesses were drained in the region of his left tibia, left elbow, left knee, right shoulder, right clavicle, and left metatarsus, sometimes more than once, involving six separate visits to the operating-theatre. During this period penicillin-resistant Staph. aureus was cultured from his blood and from the abscesses. He remained ill, with a high temperature, and his pneumonia showed no signs of resolution. The cloxacillin supply was exhausted and Bactrim two drapsules twice daily was given. The temperature returned to normal within five days. Bactrim therapy was continued for a total of 77 days without any signs of marrow depression. The left tibia showed signs of sequestrum formation, but all the other sites of osteomyelitis were clinically quiescent when he was discharged from hospital 14 days after the end of treatment.

Case 5.-A 50-year-old woman was admitted with a history of pain in the right thigh and a productive cough for two weeks during which she had had treatment with penicillin. On examination she was febrile, jaundiced, and uraemic; she had swelling and pronounced tenderness over the lower right femoral shaft, and pneumonia affecting the right middle lobe. A diagnosis of osteomyelitis with septicaemia and bronchopneumonia was made. A course of penicillin and tetracycline produced no improvement, and on the fifth day, after Staph. aureus had been grown from blood culture, treatment with Bactrim drapsules twice daily was started. Within one week the temperature fell, the jaundice and uraemia subsided, and the pneumonia resolved. An $x$-ray film showed osteomyelitis in the femur. Treatment was continued for one month, after which she was discharged, quite well and without residual bone tenderness.

Case 6.-A 10-year-old boy was admitted with a high fever, jaundice, and multiple tender swellings over the scalp, left clavicle, left humerus, left elbow, left wrist, left buttock, left ankle, and right leg. Three weeks before admission he had had a septic lesion after an injury to the right thigh. Staph. aureus resistant to penicillin was cultured from a septic skin lesion and from the blood. $X$-ray films of the wrists, arms, and both legs showed no abnormalities. He was treated as a case of staphylococcal septicaemia initially with penicillin, streptomycin, and tetracycline; he did not improve, and five days later these were replaced by cloxacillin. Surgical drainage of multiple abscesses that had developed in the sites mentioned failed to produce any improvement and new abscesses developed. Two weeks after admission, $x$-ray films showed signs of osteomyelitis in both tibiae, fibulae, humeri, and femoral heads. There was bilateral dislocation of the hips. Cloxacillin therapy was stopped after 21 days and was replaced by Bactrim two drapsules twice daily. Within four days the temperature became normal and his general condition had improved greatly. No new abscesses developed. Treatment with Bactrim was still being given at the time of writing.

The details of the above cases are summarized in Table I.

\section{Bacteriology}

At the time the strains of Staph. aureus were isolated from these patients the only measure of sensitivity available to us was the disc-diffusion test of trimethoprim and sulphamethoxazole in combination. Strains from Cases 1-5 were sensitive; the strain from Case 6 was not tested. Later, minimum inhibitory concentrations were determined from strains from Cases $1-5$ and are shown in Table II. The minimum inhibi-

TABLE II.-Sensitivities of Staph. aureus from Lesions

\begin{tabular}{|c|c|c|c|c|}
\hline \multirow{2}{*}{$\begin{array}{c}\text { Staph. } \\
\text { aureus } \\
\text { from } \\
\text { Case } \\
\text { No. }\end{array}$} & \multicolumn{3}{|c|}{ Minimum Inhibitory Concentration ( $\mu \mathrm{g} . / \mathrm{ml}$.) of: } & \multirow{2}{*}{$\begin{array}{c}\text { Potentiation } \\
\text { of } \\
\text { Trimethoprim }\end{array}$} \\
\hline & Sulphamethoxazole & $\begin{array}{c}\text { Trimethoprim } \\
\text { Alone }\end{array}$ & $\begin{array}{l}\text { Trimethoprim with } \\
\text { Sulphamethoxazole }\end{array}$ & \\
\hline $\begin{array}{ll}1 & \cdots \\
2 & \cdots \\
3 & \cdots \\
4 & \cdots \\
5 & \ldots\end{array}$ & $\begin{array}{r}4 \\
32 \\
2 \\
8 \\
4\end{array}$ & $\begin{array}{l}0.12 \\
0.12 \\
0.12 \\
0.5 \\
0.25\end{array}$ & $\begin{array}{l}0.03 \\
0.12 \\
0.03 \\
0.12 \\
0.12\end{array}$ & $\begin{array}{l}\text { Fourfold } \\
\text { Onefold } \\
\text { Fourfold } \\
\text { Fourfold } \\
\text { Twofold }\end{array}$ \\
\hline
\end{tabular}

tory concentration was less than the usually attainable blood concentration of trimethoprim for all strains and of sulphamethoxazole for all strains except that from Case 2.

\section{Discussion}

Antibiotics and general measures alone will cure more than $95 \%$ of osteomyelitis treated before the third day of illness, whereas almost $50 \%$ of patients seen after this time need surgical drainage of subperiosteal abscesses and sequestrectomies, despite adequate and prolonged antibiotic therapy (Harris, 1960). In Uganda, however, the clinician rarely sees acute osteomyelitis during the very early stages. Most patients have radiographic evidence of bone infection when admitted, indicating progressive disease of at least 10 days' duration. Such cases, as Harris showed, usually need surgical drainage of abscesses in addition to adequate chemotherapy. Many develop chronic osteomyelitis and need sequestrectomy. But for those who recover after adequate antibiotic therapy and drainage of abscesses it is not possible to say to what extent the cure can be attributed to the antibiotic. Clearly, the efficacy of a drug would be best shown by studying its effects in early acute osteomyelitis, before the development of intramedullary or subperiosteal abscesses and before the development of bone necrosis and sequestration.

During the initial phases of the treatment of patients reported here, penicillinase-resistant penicillins were very scarce in

TABLE I.-Case Summaries

\begin{tabular}{|c|c|c|c|c|c|c|c|c|c|c|}
\hline \multirow{2}{*}{ Case No. } & & \multirow{2}{*}{ Sex } & \multirow{2}{*}{$\begin{array}{l}\text { Age in } \\
\text { Years }\end{array}$} & \multirow{2}{*}{ Site of Lesions } & \multicolumn{2}{|c|}{$\begin{array}{l}\text { Staph. aureus } \\
\text { Cultured from }\end{array}$} & \multicolumn{2}{|c|}{$\begin{array}{c}\text { Trimethoprim* } \\
\text { Treatment }\end{array}$} & \multirow{2}{*}{$\begin{array}{l}\text { Days of } \\
\text { Treatment Before } \\
\text { Temp. Normal }\end{array}$} & \multirow{2}{*}{ Result } \\
\hline & & & & & Lesion & Blood & Days & $\begin{array}{c}\text { Total } \\
\text { Dose(mg.) }\end{array}$ & & \\
\hline $1 \ldots$ & . & $F$ & 7 & Right femur & + & & 42 & 6,720 & 3 & Excellent \\
\hline $2 \ldots$ & $\ldots$ & $M$ & 13 & $\begin{array}{l}\text { Left femur } \\
\text { Right femur } \\
\text { Right elbow ioint } \\
\text { Right humerus }\end{array}$ & + & + & 45 & 7,200 & 9 & Excellent \\
\hline $3 \ldots$ &. & $\mathbf{F}$ & 2 & Left tibia & + & & 28 & 4,480 & 4 & Excellent \\
\hline $4 \ldots$ & .. & $\mathbf{M}$ & 14 & $\begin{array}{l}\text { Left tibia } \\
\text { Left ulna } \\
\text { Right ulna } \\
\text { Right humerus } \\
\text { Left humerus } \\
\text { Right clavicle } \\
\text { Pneumonia and lung abscess }\end{array}$ & $\begin{array}{l}+ \\
+ \\
+ \\
+ \\
+ \\
+\end{array}$ & + & 77 & 17,280 & 5 & $\begin{array}{l}\text { Alive and well. } \\
\text { Sequestrectomy } \\
\text { Left tibia } \\
\text { required }\end{array}$ \\
\hline $5 \ldots$ & $\ldots$ & $\mathbf{F}$ & 50 & $\begin{array}{l}\text { Right femur } \\
\text { Bronchopneumonia }\end{array}$ & & + & 28 & 8,960 & 7 & Excellent \\
\hline $6 \ldots$ &. & $M$ & 10 & $\begin{array}{l}\text { Right and left femur } \\
\text { Right and left tibia } \\
\text { Right and left humerus } \\
\text { Many soft tissue abscesses }\end{array}$ & $\begin{array}{l}+ \\
+\end{array}$ & + & 147 & 47,000 & 4 & Excellent \\
\hline
\end{tabular}

-Trimethoprim given with sulphamethoxazole in 1:5 ratio respectively. 
Uganda. The combined disc-diffusion tests of staphylococci from Cases 1-5 suggested that trimethoprim-sulphamethoxazole would be effective, as it indeed was. Later, when minimum inhibitory concentrations were determined, a rational basis for this treatment was confirmed for Cases 1, 3, 4, and 5. The strain from Case 2, however, was resistant to sulphamethoxazole. In retrospect, we think that, had the minimum inhibitory concentration tests been available to us at the time, it would have been wiser to treat this patient with cloxacillinif it could have been obtained. The satisfactory response to Bactrim in Case 2 was presumably due to the independent action of trimethoprim, on which it is recommended that one should not rely (Bushby, 1969).

It is well known that acute osteomyelitis has a habit of recurring, and follow-up over a period of years is necessary before infection can be said to have been eradicated. None the less we have a strong clinical impression that trimethoprim-sulphamethoxazole is of value in the treatment of this disease. We suggest that the encouraging results obtained in these cases, four of which were septicaemic and seriously ill, establish an a priori case for the use of this drug combination in acute osteomyelitis when penicillinase-resistant penicillins cannot be used for any reason.

We are grateful to Professor I. W. J. McAdam for helpful advice in the preparation of this paper, and to Dr. J. Garrod, of Roche Products, for generous supplies of Bactrim.

Requests for reprints to be sent to Professor R. Blowers.

\section{REFERENCES}

Balmer, Susan, Pirani, A. A., and Blowers, R. (1970). In preparation. British Medical fournal, 1967, 3, 255.

British Medical fournal, 1969, 3, 728.

Bushby, S. R. M. (1969). Postgraduate Medical fournal, 45, Suppl. (November), p. 10.

Darrell, J. H., Garrod, L. P., and Waterworth, P. M. (1968). Fournal of Clinical Pathology, 21, 202. Garrod, L. P. and Waterworth, P. M. (1968). British foumal of
Venereal Diseases, 44,75.

Harris, N. H. (1960). Fournal of Bone and foint Surgery, 42B, 535.

Jensen, K., and Lassen, H. C. A. (1969). Quarterly Fournal of Medicine, 38, 91.

\section{Preliminary Communications}

\section{Phenytoin Tolerance Tests}

British Medical fournal, 1970, 3, 203-204

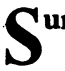
mmary: Oral and intravenous phenytoin tolerance tests showed distinctive biphasic curves with a fall in plasma phenytoin to very low levels after an initial peak and a rise to a secondary peak one to four hours later. It is suggested that this pattern should be borne in mind when intravenous phenytoin is being used, as in the control of status epilepticus or cardiac arrhythmias.

\section{INTRODUCTION}

Phenytoin (diphenylhydantoin) is widely used in the treatment of epilepsy and sometimes in the control of cardiac arrhythmias (Bigger et al., 1968). In an attempt to provide a standard measure of absorption of the drug, oral and intravenous tolerance tests were devised. Unexpectedly, the tolerance curves so obtained showed a double peak.

\section{METHOD}

Oral Tolerance Test.-Phenytoin sodium $700 \mathrm{mg}$. in capsule form (Epanutin) was given as a single dose to fasting adult subjects. Heparinized blood samples for estimation of plasma phenytoin levels were obtained before the drug was given and at the following times afterwards: 30 minutes, one hour, hourly from two to eight hours, 10 hours, and 12 hours. The plasma was separated by centrifugation, frozen, and stored until estimated.

Intravenous Tolerance Test.-Phenytoin sodium $250 \mathrm{mg}$. was injected intravenously into fasting adult subjects at a rate of $25 \mathrm{mg}$. a minute. Plasma samples were obtained before the injection and at 5, 15, and 30 minutes, one hour, hourly from two to eight hours, and 10 hours, timed from the end of the 10-minute injection period. They were frozen and stored until estimated.
Subjects.-Ten subjects had oral and four subjects had intravenous tolerance tests. They were either patients with epilepsy about to start anticonvulsants or volunteer long-stay neurological patients.

Estimation of Plasma Phenytoin.-Plasma phenytoin levels were estimated by the method of Svensmark and Kristensen (1963). The phenytoin was extracted by chloroform from acidified plasma and then re-extracted into a phosphate buffer of $\mathrm{pH} \mathrm{11.5.} \mathrm{The} \mathrm{concentration} \mathrm{of} \mathrm{drug} \mathrm{was} \mathrm{measured}$ by ultraviolet spectrophotometry and compared with a known standard.

\section{RESULTS}

The oral tolerance test from one of our subjects is shown in Fig. 1. The most striking feature is the biphasic nature of the curve. After a rise to $9 \mu \mathrm{g} . / \mathrm{ml}$. one hour after ingestion of phenytoin the plasma level fell to $3 \mu \mathrm{g} . / \mathrm{ml}$. at two hours and

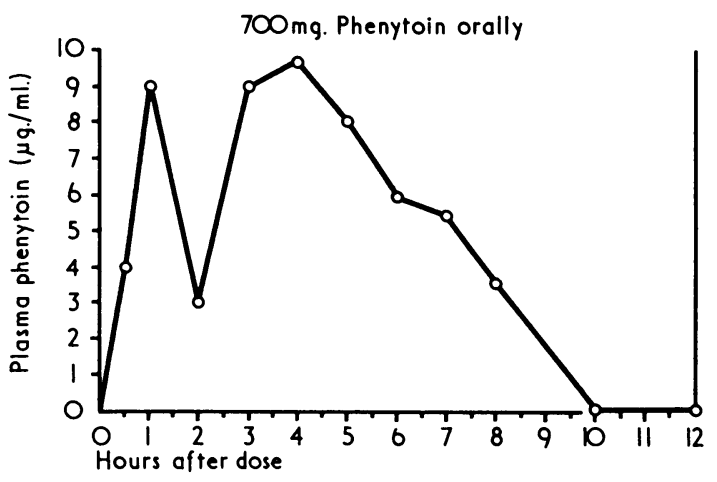

FIG. 1.-Oral phenytoin tolerance test from one of the 10 subjects studied.

rose again to $9-10 \mu \mathrm{g} . / \mathrm{ml}$. between three and four hours; the level then fell progressively. In all 10 oral tolerance tests a similar biphasic curve was seen. The oral tolerance test results for the 10 subjects studied are shown in the Table. In 